\title{
Glomerulonephritis contributing to chronic kidney disease
}

\begin{abstract}
Chronic GN leads to CKD in a significant number of cases. Timely diagnosis and proper management of glomerular diseases can prevent the progression of glomerulopathies to CKD and ESRD and can go a long way in reducing the burden of CKD, especially in developing countries. Further research is required to determine the risk factors leading to progression of glomerulopathies to CRF and ESRD.
\end{abstract}

Volume 5 Issue 4 - 2017

\author{
Rubina Naqvi \\ Department of Nephrology, Sindh Institute of Urology and \\ Transplantation (SIUT), Pakistan
}

Correspondence: Rubina Naqvi, Department of Nephrology, Sindh Institute of Urology and Transplantation (SIUT), Karachi, 74200, Pakistan, Email naqvirubina@yahoo.com

Received: August 31, 2017| Published: October 23, 2017
Abbreviations: CKD, chronic kidney disease; ESRD, Endstage renal disease; DM, diabetes mellitus; GN, glomerulonephritis; $\mathrm{CRF}$, chronic renal failure; USRDS, united states renal data system

\section{Introduction}

Chronic kidney disease (CKD) is becoming a worldwide public health problem. ${ }^{1}$ It is reported to be around $10-15 \%$ worldwide, with a sharp increase in Asian countries. ${ }^{2-5}$ CKD is associated with increased mortality, impaired quality of life, and most importantly, increased healthcare expenditures. ${ }^{6-10}$ If left untreated, CKD will lead to end-stage renal disease (ESRD) necessitating chronic dialysis or renal transplantation. These are the only two options for patients with ESRD. Hence, the attention is focused to diagnose and treat kidney disease at an early stage. A big impediment is relative dearth of nephrology services and facilities in developing countries. ${ }^{11-15}$ In the context of early recognition and prevention of renal disease, it is important to analyze the prevalent etiological factors of CKD in a particular population. It is well known that the epidemiology and etiology of CKD vary widely, depending on geographic location, race and ethnic background. However, the studies dealing with epidemiology of CKD are fraught with problems related to definition of CKD. Following the initiative of KDIGO for standardizing the definitions of CKD, the studies are becoming streamlined throughout the world and international communication has improved. ${ }^{16}$

Few nationwide surveys are available on this topic in the literature. Very few renal disease registries exist in the world to study the nationwide prevalence and risk factors of CKD. The situation is even more pathetic in developing countries. ${ }^{17}$ The awareness has increased in recent years regarding CKD and its early diagnosis, especially in developing countries, including Pakistan. However, the majority of these cases require immediate dialysis and etiology largely remains speculative. ${ }^{15,18-26}$ As an example, in a survey of 874 patients with chronic renal failure requiring dialysis, unknown etiology $(26.3 \%)$ was the most common group. ${ }^{17}$ The two most common causes of CKD worldwide are the diabetes mellitus (DM) and hypertension. ${ }^{1-10}$ Glomerular diseases also constitute an important cause of growing epidemic of CKD. ${ }^{17}$ However, the prevalence and incidence of glomerulopathies varies widely in different parts of the world. Similar to $\mathrm{CKD}$, there are very few national registries for documentation of glomerular diseases at a mass level. Most of the studies on glomerular diseases are single center or multi-center based. Hence, accurate data on the incidence and prevalence of glomerular diseases is still lacking or at primitive stage in most countries. Moreover, there has been a change in frequency of this etiology of CKD over last 2-3 decades. Chronic glomerulonephritis (GN) was a leading cause in dialysis patients in early 1990s in Pakistan, for example. ${ }^{18,19}$ Chugh from India also found chronic GN as the number one cause of ESRD in their study followed by diabetic nephropathy $(14 \%)$, chronic tubulointerstitial nephritis (14\%) and nephrosclerosis $(13 \%){ }^{20}$

Another study from India also found chronic GN as the predominant cause of ESRD in adult patients (49.4\%) followed by diabetic nephropathy (28.4\%). ${ }^{21}$ Naicker from South Africa also reported chronic GN as the leading cause of chronic renal failure (CRF) and $\operatorname{ESRD}(25 \%)$ followed by hypertension $(20 \%) .{ }^{22}$ In contrast, data from United States Renal Data System (USRDS) shows that diabetes is the leading cause of ESRD (42.9\%) followed by hypertension (26.4\%) and glomerulonephritis (9.9\%) in the US population. ${ }^{23}$ In mid-2000 study, the glomerular disease constituted only $9.9 \%$ of CRF in Pakistan. ${ }^{17}$ In this later study, the cause was unknown in the majority of cases of CRF. ${ }^{17}$ Very few of the above studies have mentioned the criteria for the diagnosis of glomerular diseases and the figures may be considered at best as only estimates of the true picture. As suggested by Rizvi et al. ${ }^{17}$ the lower incidence of GN may be due to mis-classification of chronic GN cases as hypertensive nephrosclerosis of unknown causes. ${ }^{17}$ They included only biopsy-proven cases of GN or where the history was strongly suggestive of chronic GN. ${ }^{17}$ All types of glomerulopathies can lead to CKD. However, the rate of progression and the proportion of patients developing CKD vary significantly. It is of utmost importance to diagnose glomerular diseases at an early stage. The cases of GN should also be referred to specialist care for an optimal management. ${ }^{24,25}$

\section{Acknowledgements}

I want to thank all the authors for their valuable effort in this manuscript.

\section{Conflicts of interest}

The authors declare that there are no conflicts of interest regarding the publication of this paper. 


\section{Funding}

None.

\section{References}

1. ESRD Incidence Study Group, Stewart JH, McCredie MR, et al. Geographic, ethnic, age-related and temporal variation in the incidence of end-stage renal disease in Europe, Canada and the Asia-Pacific region, 1998-2002. Nephrol Dial Transplant. 2006;21(8):2178-2183.

2. Sakhuja V, Sud K. End-stage renal disease in India and Pakistan:burden of disease and management issues. Kidney Int Suppl. 2003; (83):S115S118.

3. Abraham G, Varughese $\mathrm{S}$, Thandavan $\mathrm{T}$, et al. Chronic kidney disease hotspots in developing countries in South Asia. Clin Kidney J. 2016;9(1):135-141.

4. Sakhuja V, Kohli HS. End-stage renal disease in India and Pakistan: incidence, causes, and management. Ethn Dis. 2006;16(2 Suppl 2):S2$20-23$.

5. Khan S, Hussain T, Salahuddin N, Mehreen S. Risk Factors of End Stage Renal Disease in Peshawar, Pakistan:Odds Ratio Analysis. Open Access Maced J Med Sci. 2016;4(3):381-387.

6. Khan S, Hussain T, Azam H, Salahuddin N. Statistical Study of Risk Factors of End Stage Renal Failure in Peshawar, Pakistan. Open Access Maced J Med Sci. 2015;3(1):189-194.

7. Ullah K, Butt G, Masroor I, Kanwal K, et al. Epidemiology of chronic kidney disease in a Pakistani population. Saudi J Kidney Dis Transpl. 2015;26(6):1307-1310.

8. Imran S, Sheikh A, Saeed Z, et al. Burden of chronic kidney disease in an urban city of Pakistan, a cross-sectional study. J Pak Med Assoc. 2015;65(4):366-369.

9. Jessani S, Bux R, Jafar TH. Prevalence, determinants, and management of chronic kidney disease in Karachi, Pakistan - a community based cross-sectional study. BMC Nephrol. 2014;15:90.

10. Alam A, Amanullah F, Baig-Ansari N, et al. Prevalence and risk factors of kidney disease in urban Karachi:baseline findings from a community cohort study. BMC Res Notes. 2014;7:179.

11. Ali Jaffar Naqvi S. Nephrology services in Pakistan. Nephrol Dial Transplant. 2000;15(6):769-771.
12. Jafar TH.The growing burden of chronic kidney disease in Pakistan. $N$ Engl J Med. 2006;354(10):995-997.

13. Sakhuja V, Kohli HS (2006) End-stage renal disease in India and Pakistan: incidence, causes, and management. Ethn Dis. 2006;16(2 Suppl 2):S2-20-23.

14. Jha V. Current status of end-stage renal disease care in South Asia. Ethn Dis. 2006;19(Suppl 1):S1-27-32.

15. Jafar TH (2006) $71 \%$ of patients with newly diagnosed chronic kidney disease progressed to renal replacement therapy or death within 3 years. Evid Based Med. 2006;11(4):118.

16. Tamizuddin S, Ahmed W (2010) Knowledge, attitude and practices regarding chronic kidney disease and estimated GFR in a tertiary care hospital in Pakistan. J Pak Med Assoc. 2010;60(5):342-346.

17. Rizvi SA, Manzoor K. Causes of chronic renal failure in Pakistan:a single large center experience. Saudi J Kidney Dis Transpl. 2002;13(3):376379 .

18. Rizvi SA, Naqvi SA. Renal replacement therapy in Pakistan. Saudi $J$ Kidney Dis Transplant. 1996;7(4):404-408.

19. Kumar H, Alam F, Naqvi SA. Experience of hemodialysis at the kidney center. J Pak Med Assoc. 1998;42:234-236.

20. Chugh KS (1998) Renal disease in India. Am J Kidney Dis. 1998;31(3):Ivii-Iix.

21. Agarwal SK, Dash SC (2000) Spectrum of renal disease in Indian adults. J Assoc Physicians India. 2000;48(6):594-600.

22. Naicker S (1996) Nephrology in South Africa. Nephrol Dial Transplant. 1996;11:30-31.

23. United States Renal Data System. Excerpts from the United States Renal Data System 2001 Annual Report. Am J Kidney Dis. 2001;4(Suppl 3):38.

24. Anees M, Ibrahim M, Adhmi SU, et al. Comparison of awareness about nephrology and kidney diseases amongst doctors in institutes with and without nephrology departments. Pak J Med Sci. 2014;30(4):891-894.

25. Yaqub S, Kashif W, Raza MQ, et al. General practitioners' knowledge and approach to chronic kidney disease in Karachi, Pakistan. Indian $J$ Nephrol. 2013;23(3):184-190.

26. Saeed ZI, Hussain SA. Chronic kidney disease in Pakistan: an underrecognized public health problem. Kidney Int. 2012;81(11):1151. 